\title{
Research on the Entrepreneurial Competency Development and Innovation of Cross-Border E- Commerce Talents in Jilin Province
}

\author{
Yuxi Zhao ${ }^{1}$ Rouhua Wang ${ }^{1, *}$ \\ ${ }^{1}$ Changchun Institute of Technology, Changchun, Jilin 130022, China \\ "Corresponding author. Email: wrhwin@163.com
}

\begin{abstract}
Cross-border e-commerce is a newly emerging major, but the theoretical and practical system of talent training is not perfect at the present stage. The knowledge structure, skills and quality requirements in talent training objectives are not clear yet, and these aspects need to be constantly updated through practice. In addition, the relevant policies, venues, funds, teachers and other educational support system also need to be further improved. This paper uses a variety of research methods and obtains research findings in the following two aspects. The research on entrepreneurial competence shows that the study on entrepreneurial competence based on the process view can integrate the advantages of trait theory and context view, making the connotation of competency richer. And the research about the entrepreneurial competency cultivation and government administrative drive, entrepreneurial competence training of cross-border e-commerce talents, which show the findings are reflected in entrepreneurial competence training should be on business school entrepreneurship education and cultivation of entrepreneurial competence and cooperation with industry and university. These research aspects mainly concern cooperative education mechanism between government, industry and school. At the same time, this paper gives research inspiration from the following four aspects: the composition of entrepreneurial competence of cross-border e-commerce talents; the constitution of the training mechanism of cross-border e-commerce talents' entrepreneurial competence; operating mechanism of the entrepreneurial competence training mechanism for cross-border e-commerce talents; countermeasures to optimize the entrepreneurial competency training mechanism of cross-border e-commerce merchants in China.
\end{abstract}

Keywords: Cross-border e-commerce, Talent training, Entrepreneurial competence.

\section{INTRODUCTION}

With the development of modern global information technology and the intensification of economic integration, China's cross-border ecommerce industry has entered a period of explosive growth. Now China's demand for innovative and entrepreneurial cross-border ecommerce talents is increasing day by day. However, China's current cross-border e-commerce talent training mechanism is not perfect, and there are still problems such as insufficient quantity and low quality of talent training. Such a situation has

*Fund: This article is supported by the following grant: Study on the promotion strategies of cross-border e-commerce innovation and entrepreneurship among university students in Jilin Province (20200101085FG) become an important bottleneck restricting the development of cross-border e-commerce industry. In this context, this paper takes applied undergraduate talents in the field of cross-border ecommerce entrepreneurship as the research object, and discusses the composition of cross-border ecommerce talents' entrepreneurial competence, as well as the construction and operation of the cultivation mechanism of entrepreneurial competence.

At present, the Yangtze River Delta and the Pearl River Delta are the main gathering areas of cross-border e-commerce in China because of their advantages in the production and manufacturing of international logistics talents and original foreign trade. Their business mainly focuses on clothing, 
shoes, hats, sports equipment and household products. According to the statistics of researches and media, Chinese total cross-border e-commerce import and export trade reached 1.3 trillion yuan in $2001,13.1$ trillion yuan in 2021, and is expected to reach 21 trillion yuan in 2035. The average annual growth rate is expected to be $20 \%$ from 2001 to 2021.

As cross-border e-commerce industry of China has gradually entered the golden period of development, the demand for talents is increasingly booming. However, the bottleneck of talents is becoming increasingly prominent at this stage. Firstly, compared with the market demand, the overall supply of cross-border e-commerce talents in China is insufficient, for example, the shortage of cross-border e-commerce talents in 2015 accounts for about $35 \%$ of the total demand. Secondly, the structure of talent team is not reasonable. High-level talents, especially innovative and entrepreneurial talents, are in lack of traditional manufacturing and foreign trade enterprises that need technical and marketing talents to build e-commerce platforms and promote enterprise transformation and upgrading. Crossborder electricity companies are more in need of operation management talents to promote enterprise development. In addition, cross-border e-commerce is an emerging industry, compared with the traditional industry business is broad To the employees of creative ability and quality request is higher In short, China's current cross-border electricity traders to size not enough talent quality is not high, lead to high attrition rates at crossborder electricity enterprise. The shortage of innovative and entrepreneurial talents and the high cost of human resources have become an important factor restricting the development of the whole industry.

\section{SIGNIFICANCES AND VALUES}

\subsection{Significances}

Colleges and universities are the main body of talent training and implementation, and also the main position of talent training for cross-border ecommerce merchants in China. The training mechanism of cross-border e-commerce talents in universities is also the most important link of the training mechanism of cross-border e-commerce talents in China. For a long time, Chinese colleges and universities have tended to implement degree education based on the evaluation system of education administrative departments and the schools themselves, which has resulted in the disconnection between university education related to cross-border e-commerce and social and industrial development, resulting in the dislocation of the specification, quality and market demand of talents trained by the schools. At present, in the training of cross-border e-commerce talents, universities often pay too much attention to theoretical education while ignoring practice, and innovation and entrepreneurship education has not been integrated into the professional curriculum system. Therefore, due to the lack of professional practice training, career planning and innovation and entrepreneurship education related to crossborder e-commerce, many graduates are weak in practical and practical problem-solving ability and team consciousness, and are difficult to adapt to the needs of relevant positions in e-commerce enterprises. After many enterprises recruit graduates, they need to add a lot of costs to implement pre-job and on-job training to make up for the lack of school education.

\subsection{Research Values}

By means of cross-border electricity traders to entrepreneurial competence cultivation mechanism of literature study, at home and abroad about the research of entrepreneurial competence and entrepreneurial education is relatively abundant, focused on entrepreneurship, entrepreneurial competence and entrepreneurial performance, such as concept definition, entrepreneurial competence cultivation and policy, the discussion of the relationship between the industry level, as well as the entrepreneurship education model reform of colleges and universities. However, there are few systematic studies on the cultivation of entrepreneurial competence of cross-border ecommerce merchants. To be specific, there are still some deficiencies in the current research in this field. The value of this paper is mainly reflected in the following aspects:

From the perspective of research content, there are deficiencies in the research on the concept, connotation and training mechanism of crossborder e-commerce talent entrepreneurial competence. Although there are many related researches on entrepreneurial competence, previous scholars only put forward the preliminary concept of entrepreneurial competence, and have not reached a unified conclusion about what subdimensions entrepreneurial competence should 
include. At the same time, although previous studies have mentioned the influencing factors and training mechanism of entrepreneurial competence, there is still a lack of in-depth discussion on how these factors influence entrepreneurial competence and how the training mechanism operates. However, there are fewer researches on the entrepreneurial competency characteristics and training of cross-border e-commerce talents.

From the perspective of research, researches related to entrepreneurial competence training tend to focus on some aspects of entrepreneurship education in universities, government policy guidance, school-enterprise cooperation training and so on. From the perspective of talent training system in colleges and universities, the content mainly discusses teaching objectives, curriculum outline, teaching methods, practice models and so on. However, there are not many researches on the construction of entrepreneurial competence training mechanism from the perspective of "government, industry and university" collaboration, and even fewer researches on the talent of cross-border ecommerce.

From the perspective of research methods, previous researches on entrepreneurial competence and its training mechanism mainly focus on theoretical discussion and qualitative research, while empirical and quantitative analysis research is relatively lacking. Although there are abundant researches on college students' entrepreneurial competence and its cultivation, there are still few researches on cross-border e-commerce talents' entrepreneurial competence, especially empirical studies and quantitative analysis.

Overall, although in recent years entrepreneurship theory and practice of cultivating the ability of university students is a hot spot of academic circles, but for cross-border electricity traders of entrepreneurial competency system research is still rare, especially by means of empirical study, through quantitative analysis method to discuss cross-border electricity traders to entrepreneurial competence and its cultivation mechanism is a lack of research.

Therefore, it has become a necessary and urgent topic to construct and improve the training mechanism of cross-border e-commerce talents' entrepreneurial competence in cooperation with government, industry and academia, carry out research on related topics, and especially explore the formation and operation mechanism of crossborder e-commerce talents' entrepreneurial competence and training mechanism through empirical research and quantitative analysis methods. In order to make up for the deficiency, this paper has great application value.

\section{RESEARCH CONTENTS}

\subsection{Main Research Contents}

Based on the management research methodology, to question the theory model is set up the idea of a theoretical model verification and correction of the theoretical model research logic to solve practical problems, to explore cross-border electricity traders to theoretical models of entrepreneurial competence cultivation mechanism and application, in order to solve optimizing our country cross-border electricity traders to entrepreneurial competence cultivation mechanism of practical problems. This paper at the early stage of the literature reading and the interviews and case studies on the development of the tomb, in combination with the human capital theory, triple helix theory and synergetic theory, established a cross-border electricity businessmen to the theoretical model of entrepreneurial competence cultivation mechanism design, and then through the large sample questionnaire investigation and mathematical statistics analysis, verification and correction of theory model, conceived by the applied theory model. Based on the analysis of the construction and operation of the training mechanism of cross-border e-commerce talent entrepreneurial competence in China, as well as the existing problems, this paper puts forward the countermeasures to optimize the training mechanism of cross-border e-commerce talent entrepreneurial competence in China.

\subsection{Key Research Problems}

This paper proposes countermeasures to optimize the entrepreneurial competence training mechanism of cross-border e-commerce talents in China from the perspective of government administrative drive, university entrepreneurship education, industrial collaborative training and "government, industry and university" collaboration.

The research focuses are as follows:

- Perfecting the government's administrative drive mechanism under the guidance of talent training strategy; 
- Improving entrepreneurship education mechanism and strengthen innovation education;

The research difficulties are as follows:

- Improving the industrial collaborative education mechanism and increase the investment in talent training;

- Improving the collaborative system of government, industry and education, and optimize the collaborative education mechanism.

\subsection{Main Innovations}

This paper takes cross-border e-commerce talents as the research object, and from the perspective of cooperation between government, industry and education, comprehensively uses literature method, interview and case method, grounded research method and questionnaire method to conduct qualitative and quantitative analysis on the entrepreneurial competence and training mechanism of cross-border e-commerce talents, and tries to make the following innovation points:

\subsubsection{Establishing a Theoretical Model of Talent Entrepreneurship Competency Training Mechanism for Cross-border E-commerce Merchants}

Based on relevant literature research, theoretical application and empirical research, this paper defines the concept of entrepreneurial competence of cross-border e-commerce talents and tries to reveal the characteristics of entrepreneurial competence. On this basis, the key training factors affecting the development of cross-border ecommerce talent entrepreneurial competence are extracted, so as to construct the theoretical model of the training mechanism of cross-border ecommerce talent entrepreneurial competence in China, and further explore the composition and operation mechanism of the training mechanism of cross-border e-commerce talent entrepreneurial competence.

\subsubsection{Discussing the Countermeasures and suggestions for optimizing the Talent Entrepreneurship Competency Training Mechanism of Cross-border E- commerce Merchants in China}

Based on the theoretical model of the training mechanism of cross-border e-commerce talents' entrepreneurial competence obtained from the research and the analysis of the current situation and shortcomings of China's existing training mechanism, this paper puts forward countermeasures and suggestions to optimize the training mechanism of cross-border e-commerce talents' entrepreneurial competence, striving to give full play to their ability to discover, analyze and solve practical problems.

\subsection{Research Methods}

According to the research purpose and the properties of the research object, the main methods applicable to this paper are behavioral event interview method, literature study method, expert group method, questionnaire survey method, case method and grounded research method.

\subsubsection{Behavioral Event Interview}

Professor McClelland of Harvard University used the open behavior review survey technique to ask respondents to review the work history of their positions, tell the most successful and unsuccessful events they experienced, describe in detail the working situation they were in and the causes and consequences of the events, review their coping strategies and specific actions at that time. And the final outcome and impact of the event. Through the analysis of the interview data, the differences between the top performers and the average performers are identified, so as to summarize and define the competency model of this job. Through this "behavioral event interview method", interviewees are easy to collect more authentic data and obtain more information, and it is easy to find out the key factors of competence that affect job performance. Therefore, it is an effective way to analyze competency characteristics and construct competency model. Behavioral event interview is also the most effective competency modeling method recognized by scholars.

However, this method also has some limitations. First of all, behavioral event interview requires high professional knowledge and skills of 
model builders. First, it requires good cooperation of interviewees, so it is difficult to implement. Secondly, in the behavioral event interview method, the interviewees' description of key events is often paid attention to, and the key factors affecting job performance are summarized through the analysis of key events, and then the competency characteristics are analyzed and concluded. Other relatively important job competency elements may be missed. Finally, the behavioral event interview emphasizes the respondents' review of past behaviors, but fails to take into account the fact that the enterprise is in different development stages and different situation changes, so the corresponding job competency requirements are constantly changing.

\subsubsection{Literature Research}

Literature research method is to collect relevant literature and analyze the basis of previous researches: preliminarily determine the competency model and characteristics. Although the literature research method is relatively simple and fast, the collected data are often secondary, and the competency model constructed is not accurate enough. Therefore, researchers are usually required to flexibly use a variety of methods, such as behavioral event interview and questionnaire.

\subsubsection{Expert Group Method}

Expert group method is to invite experts who are very familiar with the target position to form a group, and then they describe in detail the competency requirements of the workers in this position. By collecting and identifying the opinions of the experts, the competency model of the position is established.

\subsubsection{Questionnaire Survey}

Questionnaire can be divided into open questionnaire and closed questionnaire. Questionnaire survey method has the advantages of fast, convenient and low cost, and can collect a large amount of data and other information. Among them, the open questionnaire is to collect the key behavioral examples of the target position in the organization, and then define the relevant competency characteristics. On the other hand, the closed questionnaire is a preliminary summary of the competency characteristics of specific jobs by the researchers on the basis of various methods such as behavioral event interview method and literature method. Then these competency characteristics are prepared into a questionnaire for quantification, and then the competency model is defined through questionnaire issuance, recovery and data effective analysis. For typical work cases, the open questionnaire can collect a lot of information, but the validity of the sample is difficult to obtain. In the process of information collection and competency model construction, the closed questionnaire adopts the method of quantitative analysis, which is relatively scientific. The disadvantage of the closed questionnaire is that it requires researchers to do a high level of research work in the early stage. Since information is collected through the questionnaire based on the competency model preliminarily constructed in advance, additional data and information are not easy to be paid attention to and collected.

\subsubsection{Case Study Method}

Case study is a comprehensive and in-depth study conducted by selecting typical cases as samples for the research purpose and the overall research object. Summarize the results of the sample text, so as to infer the characteristics of the whole from the attributes of the sample.

\section{RESEARCH FINDINGS}

\subsection{Research on Entrepreneurial Competence}

The number of college students starting businesses in the field of cross-border e-commerce is increasing year by year, and the problem of insufficient entrepreneurial ability is becoming increasingly prominent. In "peoples innovation and entrepreneurship" era background, because of the college students is the major force of society's most innovative and entrepreneurial potential, develop and implement innovative entrepreneurship education of university scientific development strategy, we will deepen reform of the personnel training and encourage students to independent entrepreneurship to create more employment opportunities, is a response to innovative national construction strategy, and the needs of the development of school-based. Since cross-border ecommerce is relatively easy to start a business, low cost and risk, and high profit, the development of cross-border e-commerce industry provides students with good entrepreneurial opportunities and platforms, with broad prospects for development. Therefore, the number of college 
students who choose to start businesses in the field of cross-border e-commerce is increasing year by year.

However, while college students are full of passion and entrepreneurship, they also encounter the bottleneck of their entrepreneurial ability. Students are weak in the application of cross-border e-commerce technology and innovation ability, and lack of experience in team management, market operation and risk control, leading to a relatively single entrepreneurial model. Most students choose third-party network platforms to establish and operate online stores. Although this mode has small investment, quick results and simple and flexible operation, it is easy to cause excessive competition of homogeneity and even market chaos. As a result, the profit of the operation is generally low, or even at a loss.

Based on previous studies, it can be found that the research perspective of entrepreneurial competence has undergone a transformation from trait theory to situational view and then to process view. The "trait theory" emphasizes the extraction of entrepreneurial competence from the individual characteristics of successful entrepreneurs, and fails to realize the impact of different entrepreneurial situations entrepreneurs face on their competence. View "and the" situation of entrepreneurial competence study took into account the different business situations of competency requirements, but ignores the different stages of entrepreneurship is a continuous dynamic process, with the deepening of entrepreneurship, entrepreneur role in shifting, the corresponding entrepreneurial competence also in development, so as to complete the various stages of the task. The research on entrepreneurial competence based on the process view can integrate the merits of trait theory and situation view and enrich the connotation of competency.

\subsection{Research on the Entrepreneurial Competence Training of Cross-border E-commerce Talents}

\subsubsection{Entrepreneurial Competency Cultivation and Government Administrative Drive}

The government is the coordinating force for the country's economic and social development. The government often takes measures such as policy and regulation guidance, talent guarantee, incubation platform support and special funding to drive the cultivation of entrepreneurial talents. It involves measures such as creating a legal environment, cultivating talents and starting business plans, providing government credit guarantee, implementing tax incentives, setting up entrepreneurship parks or incubators to provide entrepreneurial support, and funding for entrepreneurship and entrepreneurship education to support entrepreneurship education and encourage entrepreneurship.

\subsubsection{Entrepreneurial Competency Cultivation and Entrepreneurial Education in Business Schools}

This paper argues that the entrepreneurial competence is entrepreneurs to adapt to the business environment, successful entrepreneurial activities and processes, and achieve high performance, have individual character, knowledge, skills, and so on comprehensive competence characteristics, this article's cross-border ecommerce talents competence on education, practice skills of competency can be obtained. There are many methods to construct competency model, including behavioral event interview method, literature method, etc., among which behavioral event interview method is recognized as the most effective method. According to the purpose of this paper and the characteristics of the research object, this paper is suitable for the comprehensive use of literature method, behavioral event interview method, case method, expert method and questionnaire survey method and other methods. McLelland's competency model building procedures are: establishment of performance standards, sample analysis, data collection and analysis, construction and verification model, which are steps based on behavioral interview method, and provide strong theoretical support and methodical reference for this paper to mine the entrepreneurial competency characteristics of crossborder e-commerce talents and construct competency model.

\subsubsection{Cultivating Entrepreneurial Competence and Cooperating with Industry and University}

Through the review of relevant literature on entrepreneurial competence cultivation at home and abroad, it is not difficult to find that the entrepreneurial competence of cross-border ecommerce talents can be cultivated, and it can be 
realized through the collaborative cultivation of "government, industry and science". Therefore, cross-border e-commerce talents with entrepreneurial potential can become entrepreneurs through training. The "feasibility" of entrepreneurial competence training provides a logical basis for the follow-up research on the cultivation mechanism of cross-border e-commerce talents' entrepreneurial competence.

\subsubsection{Study on the Mechanism of Collaborative Education of "Government, Industry and Science"}

In the context of globalization and transformation and upgrading of traditional economy, there is a phenomenon that the university is not closely connected with the government and industry or even separated from it in the development of higher education. Entrepreneurship education in colleges and universities is a complex and systematic project, entrepreneurship education should pay attention to the needs of the development of market economy and more collaborative education resources, to create the open entrepreneurship education organization and operation mechanism, the main body of education is not confined to college teachers, but needs the cooperation with government, industry and other external organizations, establish an effective multiple subject to participate in cooperative education mechanism. Reference to previous research, we believe that for entrepreneurial competence of cross-border e-commerce talents cultivation, we can build based on the three strategic synergy between production and cultural system of coordination, organization, coordination and collaboration content such as collaborative education mechanism, so as to achieve synergy of entrepreneurship education resources, in order to improve the entrepreneurial competence of crossborder e-commerce talents training level.

\section{ENLIGHTENMENTS}

\subsection{The Composition of the \\ Entrepreneurial Competence of Cross- border E-commerce Talents}

Entrepreneurial competence refers to the comprehensive competence characteristics of individual personality, knowledge and skills that entrepreneurs have to adapt to the environment, successfully carry out entrepreneurial activities and processes, and achieve high performance. This paper focuses on the competence of skills. The entrepreneurial competence of cross-border ecommerce talents includes five dimensions: entrepreneurial opportunity competence, crossborder cultural competence, team building competence, business innovation competence, and entrepreneurial efficiency competence.

\subsection{The Constitution of Cross-border E- commerce Talents Entrepreneurial Competence Training Mechanism}

The entrepreneurial competence training mechanism of cross-border e-commerce talents can be constructed from the perspective of "government, industry and university" collaborative education. The training mechanism consists of three links: government administrative drive, university entrepreneurial education and industrial collaborative training. The three training links are related to each other and jointly affect the entrepreneurial competence of cross-border ecommerce talents. Each key part of the training link has different effects on the dimensions of entrepreneurial competence.

\subsection{The Operational Mechanism of Cross- border E-commerce Talent Entrepreneurial Competence Training Mechanism}

Cross-border e-commerce talent competency training mechanism can be regarded as a complex and open system. Its talent training goal led to political industry-academic cooperation strategy as direction of three parties, cultural synergy as the guide, cooperation organization as guarantee, collaborative operation for power system, so as to achieve the administrative and academic resources and production practice the accumulation of the resources of synergy in the process of talent training, thus to achieve the effect of talent training. The operation of the training mechanism of crossborder e-commerce talent entrepreneurial competence has gone through the stage of promoting the growth driven by the government and the initial construction of the training mechanism. The forming stage of the training mechanism of university and industry oriented drive and deep cooperation; and the mature stage of the multi-subject drive and the coordinated development of entrepreneurship education and society. 


\subsection{Countermeasures to Optimize the Training Mechanism of Cross-border E-commerce Talents' Entrepreneurial Competence}

Based on the theoretical model of cross-border e-commerce talent entrepreneurial competence training mechanism constructed above, this paper analyzes the current situation of the construction and operation of cross-border e-commerce talent entrepreneurial competence training mechanism in China. It is pointed out that the talent entrepreneurial competence training mechanism of cross-border e-commerce has been initially established in China, and the effect of talent training has been shown. However, the three links of government administrative drive, entrepreneurship education in colleges and universities and industrial collaborative training all need to be improved. The personnel training mechanism is still in the stage of promoting the development led by the government and improving the system. The cooperative training mechanism is not smooth and needs to be further optimized.

Finally, this paper proposes countermeasures to optimize the entrepreneurial competency training mechanism of cross-border e-commerce talents in China from the perspective of government administrative drive, university entrepreneurial education, industrial collaborative training and "government, industry and university" collaboration: 1) improve the government administrative drive mechanism under the guidance of talent training strategy;2) Improving entrepreneurship education mechanism and strengthening innovation education;3) Improve the industrial collaborative education mechanism and increase the investment in talent training;4) Improve the collaborative system of government, industry and education, and optimize the collaborative education mechanism.

\section{CONCLUSION}

In this paper, by referring to the relevant policies and documents of cross-border ecommerce innovative and entrepreneurial talent cultivation issued by the State Council and Jilin Province, as well as the relevant literature of crossborder e-commerce innovative and entrepreneurial talent cultivation at home and abroad, the situation of cross-border e-commerce innovative and entrepreneurial talent cultivation was studied. Conduct investigations in electronic industrial parks, universities and some key e-commerce enterprises, and understand the current situation and problems in the demand and development of innovative and entrepreneurial talents of crossborder e-commerce based on the relevant information learned from field investigations.

From the perspective of innovative and entrepreneurial talent training, combined with the development characteristics of cross-border ecommerce in Jilin Province, this paper gives corresponding countermeasures and suggestions, and the specific solutions mainly include three aspects:

It is suggested to put forward the strategy of establishing cross-border e-commerce as a separate major, so as to train middle and senior professional innovative and entrepreneurial talents of crossborder e-commerce in a more targeted way, so as to adapt to the new development of cross-border ecommerce;

It is proposed to promote the integrated development of innovative and entrepreneurial talents in cross-border e-commerce, which is conducive to the large-scale development of innovative and entrepreneurial talents in crossborder e-commerce and effectively solves the imbalance between supply and demand of innovative and entrepreneurial talents;

It is better to put forward the joint ventures with foreign universities, the innovation lies mainly in the output of the focus on learning language and Chinese culture, spread Kong Sheng classic, promote the fusion between Chinese and foreign culture, to promote "neighbourhood" deep implementation of national strategy, through cultural output for the cross-border business innovative entrepreneurial talent training to provide a better social environment.

The above innovative countermeasures have certain practical value, and provide theoretical support and practical reference for promoting the cultivation of innovative and entrepreneurial talents in cross-border e-commerce in Jilin Province and other regions.

\section{AUTHORS' CONTRIBUTIONS}

Yuxi Zhao is responsible for experimental design and wrote the manuscript; Rouhua Wang contributed to revising and editing. 


\section{REFERENCES}

[1] Sun Miantao, Kang Cuiping, et al., New Interpretation of Educational Mechanism Theory. Research on Education [J]. 2005(12): 22-28.

[2] Huan Chen Shusheng Reform of Expectation Cultivation Model of Higher Education [N] Guangming Daily, 2007.4.11

[3] Modern Chinese Dictionary [Z]. Beijing: The Commercial Press, 2000. 80.

[4] Wu Qiong 'en, The Relationship between Entrepreneurship Policy and Youth Entrepreneurship [D]. Master's Thesis, Taiwan Chengchi University, 2008:111-112.

[5] Mei Weihui and Xu Xiaozhou, Difficulties and Strategies of Entrepreneurship Education in Chinese Universities [J]. Educational Research, 2009 (04): 61-72.

[6] Hu Jie and Qin Hong, On the Formation of College Students' Entrepreneurial Capability [J]. China Light Industry Education, 2014 (09): 19-22.

[7] Li Liangcheng, An Analysis of the Entrepreneurship Environment of Science and Technology Enterprises - Based on the Entrepreneurship of Returned Overseas Students in Guangzhou [J]. Economist,2006 (11): p. 70-71+74.

[8] $\mathrm{Xu}$ Pingping and $\mathrm{Ye}$ Weiwei, Entrepreneurship Education Model Based on Dynamic Capability - A Case Study of Zhejiang Province $[\mathrm{J}]$. Research in Higher Engineering Education, 2010 (6) : 67-72.

[9] Chen Shujiao and Shen Chenli, A Study on the Improvement Path of College Students' Entrepreneurial Competency Based on CDIO Perspective [J]. Innovation and Entrepreneurship Education, 2005 (2) : P.4044.

[10] Honig, B., what determines success? examining the human, financial, and social capital of Jamaican microentrepreneurs [J].Journal of Business Venturing, 1998. 13(5): p. 371-394.

[11] Raposo, M. and P.A. Do, Entrepreneurship education: relationship between education and entrepreneurial activity [J]. Psicothema, 2011.23(3): p. 453-7.

[12] Allan Bud and Schon Beechler Source. Links between Business Strategy and Human Resource Management Strategy in U.S.-Based Japanese Subsidiaries: An Empirical Investigation [J]. Journal of International Business Studies, Vol. 2b, No. 11,lst Qtr.,1995, pp. 23-46

[13] Qmrane A and Fayolle A, Entrepreneurial competencies and entrepreneurial process: Dynamic approach [J]. International Journal of Business \& Globalisation, 2011, G (2):136153.

[14] Arthur K Yeung. Competencies for HR profession-als: An interview with Richard E.B oyatzis [J]. Hu-man Resource Management, Spring 1996:119-332

[15] Bamn, R.A. and G.D. Markman, Beyond social capital: the role of entrepreneurs' social competence in their financial success [J]. Journal of Business Venturing, 2003.18(1):p. 41-60.

[16] Markman, G.D. and R.A. Baron, Personentrepreneurship fit: why's people are more successful as entrepreneurs than others. Human Resource Management Review, 2003.13(2): p.281-341.

[17] Kirchhoff B Entrepreneurship's Contribution to Economics [J]. Entrepreneurship: Theory \& Practice, vol. 1 b, issue 2(1991), pp. 93-112 